\title{
Personality characteristics in a Swedish national sample of identifiable oocyte donors
}

Gunilla Sydsjö, C. Lampic, S. Brandstrom, J. Gudmundsson, P.O. Karlstrom, N.G. Solensten, A. Thurin-Kjellberg and A.S. Svanberg

\section{Linköping University Post Print}

N.B.: When citing this work, cite the original article.

This is the authors' version of the following article:

Gunilla Sydsjö, C. Lampic, S. Brandstrom, J. Gudmundsson, P.O. Karlstrom, N.G. Solensten, A. Thurin-Kjellberg and A.S. Svanberg, Personality characteristics in a Swedish national sample of identifiable oocyte donors, 2011, British Journal of Obstetrics and Gynecology, (118), 9, 1067-1072.

which has been published in final form at:

http://dx.doi.org/10.1111/j.1471-0528.2011.02953.x

Copyright: Wiley-Blackwell http://eu.wiley.com/WileyCDA/Brand/id-35.html

Postprint available at: Linköping University Electronic Press http://urn.kb.se/resolve?urn=urn:nbn:se:liu:diva-69785 
Personality characteristics in a Swedish national sample of identifiable oocyte donors.

Sydsjö Gunilla, ${ }_{1}^{1}$ Lampic Claudia, ${ }^{2}$ Brändström Sven, ${ }^{3}$ Gudmundsson Johannes, ${ }^{4}$ Karlström Per Olof, ${ }^{5}$ Solensten Nils Gunnar, ${ }^{6}$ Thurin-Kjellberg Ann, ${ }^{7}$ Skoog Svanberg Agneta ${ }^{5}$

1. Division of Obstetrics and Gynecology, Department of Molecular and Clinical Medicine Faculty of Health Sciences, Linköping University, Sweden

2. Department of Neurobiology, Care sciences and Society, Karolinska Institute, Sweden

3. Inst for Neuroscience and Physiology, Psychiatry and Neurochemistry section,

Forensic Psychiatry, University of Gothenburg, Sweden

4. Dept. Of Women's and Children's Health, Uppsala University, Uppsala, Sweden

5. Clintec, Karolinska Institutet, Dept of clinical Science, Intervention and Technology

Div. of obstetrics/gynecology, Karolinska University Hospital, Stockholm Sweden

6. IVF-kliniken Umeå in collaboration with Umeå University Hospital.

7. Inst of Clinical Sciences, Sahlgrenska Academy, Gothenburg

Correspondence: Gunilla Sydsjö,

Division of Obstetrics and Gynecology, Department of Molecular and Clinical Medicine

Faculty of Health Sciences, Linköping University,

SE - 58185 Linköping, Sweden

Tel: +4613223167; fax: +4613148156

Email: Gunilla.Sydsjo@lio.se

Short running title: Personality characteristics of identifiable oocyte donors. 


\section{Abstract}

Objective: To study personality characteristics of identifiable oocyte donors in a national sample in comparison to normal values.

Design: Descriptive study.

Setting: All Swedish donation programs

Subjects: All donors recruited during 2005-2008.

Method: Standardized questionnaires were used to measure personality

Main outcome measures: Demographics, TCI Temperament and Character instrument

Results: The majority (65\%) of the donors had biological children of their own. The results from the TCI indicate that the oocyte donors were all within the normal range of character. With regard to personality, a significant difference was evident between the two groups; oocyte donors showed lower means for Harm Avoidance and higher scores for Persistence than the controls. This indicates that the donors felt less worried and displayed a lower level of fear of uncertainty, shyness and fatigability and a higher level of persistence than the controls. In the present sample, 29 (16\%) of the donors were so called "known donors" i.e. the recipient couples and the donors were known to each other. "Known donors" displayed a mature and stable character.

Conclusion: In this nationwide oocyte donor program we found that the women who had been accepted for inclusion in the donation program were all well adjusted and mature.

Keywords: Personality, Character, Gamete donors, non anonymous 


\section{Introduction}

Altruistic motives and awareness of the distress and sorrows of being childless are the most common reasons given by female donors who donated their gametes to help others $(1,2)$.

Subjective norms and behavior control also influence the intention to donate oocytes (3). The personality characteristics of non-anonymous gamete donors and prospective non-anonymous donors and non-commercial donors have not previously been studied carefully.

There are difficulties in comparing oocyte donors with other types of donors - for example organ donors - even though there are studies of the attitudes, behaviors and motives of other types of donors including blood donors and kidney donors $(4,5)$. The most prominent reasons to become a donor of a kidney or blood are altruism and having a feeling of social responsibility toward others, although other motives based in religious belief and planned behavior have been discussed as well $(4,5)$

Each organ donation can help another person to live a better life and be free of a disease. The personality characteristics of blood donors might be expected to differ considerably from the personality characteristics of gamete donors since the circumstances involved in the two types of donations are so different. When a person gives blood the exact future use of that blood is unknown and may also be of no interest to the donor. A gamete donor, on the other hand, might be faced many years later with an individual who claims that the donor is his or her genetic mother or father and this individual might even raise questions about the motives and reasons for the donation. The wellbeing, the circumstances of the child's upbringing as well as the actual situation of the child's living situation might therefore be matters of concern for the donor both at the time of the donation and in the long run. Thus the gamete donor's choice to become a donor might affect the life of another individual or even the donor in unforeseen and diverse ways.

In Sweden, all children born as a result of gamete donation have the legal right to obtain information from the appropriate hospital about the identity of their gamete donor when these children reach the age of maturity (18 years). The law has been in effect since 1985 for sperm donation and when oocyte donation was allowed 2003 integrated in the law as well.

Worldwide gamete donation programs use both anonymous and non-anonymous donors, and in some countries the recipient couples have a legal right to obtain information about the 
donor and also to choose personality traits, religion, and education level of a prospective donor (1). The differences in laws and treatment opinions reflect the different policies, religion and ethical principles in countries.

Since Sweden was the first country to pass the non-anonymous law there has been considerable interest in other countries in what happens in Sweden as the law is implemented. Will the recipient couples inform their children, for example, and if so will the children take the opportunity to access information about their genetic origin and trace the donor and even contact the donor once the child has reached the age of maturity. Without doubt, this will have an impact on the donor and possibly on other people close to the donor when that time comes. Thus, for fertility clinics it is important to assess personality characteristics of each donor in order to be able to determine if the person willing to be a donor may be at risk of subsequently regretting having made the donation, of being ambivalent and even of displaying such a vulnerable personality that he or she might be at risk for a future psychological disorder.

There are a number of reasons that donors become donors just as there are a number of strict rules to be followed by the clinic in selecting the donors. In some countries, financial reimbursement is vital in getting donors to donate. In Sweden, however, no financial compensation is given except for travel and work expenses associated with the gamete donation. The gamete donors do not have any rights or responsibilities towards the child, either emotionally, financially or legally.

Some studies have been made in an effort to explore the reasons why individuals choose to become gamete donors and these studies suggest that the motives and feelings associated with oocyte donation differ from those associated with sperm donation (1). It appears to be more common for women to become "known donors", especially when helping a sister or a friend than for men to become "known sperm donors". There are very few studies that have explored the personality characteristics of gamete donors and the effect of a donation on the donor in the long run. An individual's personality influences her/his lifestyle and behavior and can also predict traits that will contribute to willingness to help and share as well as to determine the individual's mental health, especially susceptibility to depressive and mood disorders, which may be especially important in the donor recruitment process (6). 
The aim of the present study was to study demographic data and the personality characteristics of oocyte donors in a Swedish national sample and to investigate whether oocyte donors differ in their personality from women of comparable age in the general population. Another aim was to study if the personality characteristics of known donors differ from those of women who donate to unknown couples.

\section{Material and Methods}

The Swedish multicenter study on gamete donation is a prospective longitudinal study of donors and recipients of donated gametes including comparison groups. Study participants were recruited from all infertility clinics performing gamete donation in Sweden, clinics located at the University hospitals in Stockholm, Gothenburg, Uppsala, Umeå, Linköping, Örebro, and Malmö.

\section{Participants and procedure}

During the period April 2005 to April 2008 consecutive oocyte donors were approached regarding participation.

\section{$\underline{\text { Donors }}$}

All women who were accepted as donors of oocytes were approached for study participation. Exclusion criteria were: persons who did not speak and read Swedish. Of 220 eligible oocyte donors who were approached, $181(82 \%)$ agreed to participate and completed the first questionnaire, including the TCI. The main reasons for refraining from participating in the study were that the questions were too personal or that the TCI took too long to fill out.

\section{Comparison group}

The controls are matched according to age and gender from the normative study (7). The normative data for the Swedish TCI is based on a random sample of 2322 individuals (age 13 to 80) from the general population in Sweden. In this study the inclusion criteria for the subjects of ages above 20 years of age were to be a resident of Sweden and a Swedish citizen. They were randomly recruited by the county population register.

\section{Temperament and Character Inventory (TCI)}

The Temperament and Character Inventory (TCI) based on Cloninger's personality model was used for measuring personality characteristics (8). The model measures four dimensions of temperament and three dimensions of character. The temperament dimensions are traits, which are moderately heritable and moderately stable throughout life. These dimensions refer 
to individual differences in conditioned emotional responses, such as anger, fear, and disgust, namely novelty seeking (NS), harm avoidance (HA), reward dependence (RD), and persistence (PS). Character dimensions represent traits that are weakly inherited and moderately influenced by social learning. Character refers to individual differences in goals, values and self-conscious emotions such as shame, guilt and empathy. The character dimensions are self-directedness (SD), cooperativeness (CO), and self-transcendence (ST). Detailed descriptions of the dimensions are available elsewhere (6). The Swedish version of the TCI has been validated and its reliability has been tested in clinical and non-clinical samples (9-11).

\section{Procedur}

All donors were to meet a doctor and a psychologist to be evaluated for both physical and psychological status as well as to inform the donors to be about the law.

The potential donors were then invited to an interview with the responsible physician who informed about and discussed the medication, time commitment, legal and ethical issues. In the next step, donor candidates were assessed and evaluated by the clinic psychologists/counselor. If approved, the potential donor was registered for donation. The recommendation from the Swedish National Board of Health and Welfare (12) is that oocyte donors should preferably be between 25 and 35 years old and have children of their own.

Study participants completed a questionnaire including the TCI after being accepted in the donation program at each clinic. This assessment usually took place after the interviews and medical examination at each clinic. Participation was rewarded with gift vouchers (worth approximately 12 Euro).

\section{Demographic data}

Data on marriage status, parity, age and occupation as well as if the donor was known to the recipient couples were collected in the questionnaire.

\section{Statistics}

All analyses were performed using the SPSS program, version 17.0.1 (SPSS Inc., Chicago, IL). In order to compare mean scores of matched samples we used Paired Samples T-test. We also applied Chi-Square Tests, Contingency Coefficient in order to evaluate the association between two nominally scaled variables. In order to test for differences in personality between various family situations and known or unknown receivers we used One- 
way Anova followed by Post Hoc Tests (Tukey because of equal variances). Furthermore, multiple analyses of variance (MANOVA) was calculated with the TCI-subscales as dependent variables and known versus unknown receivers as fixed factor in the model. 


\section{Results}

Demographic characteristics are presented in Table 1. In this study, 29 (16\%) of the donors were so called "known donors" meaning that the recipient couples and the donors were known to each other. The mean age of the donors was $30.3 \pm 4.5$ years with a range from 20 -40 years. The majority (65\%) of the donors had biological children of their own with a range of from one to four children. Ten $(5.5 \%)$ of the donors had donated previously in other clinics abroad and to known recipient couples.

With regard to temperament, oocyte donors reported significantly lower scores for Harm Avoidance and higher scores for Persistance compared to the comparison group. (Table 2). This indicates that the donors were feeling less worried, fear of uncertainty, shyness and fatigability and more persistent then the controls. No significant group differences between oocyte donors and the comparison group were found for the character dimensions.

In order to test for relationships between personality traits and family situation a one-way Anova was performed. Significant differences was found for PS ( $F=3,54 ; p=0,031)$ without significant Post Hoc Test results. However, the Post Hoc Tests for SD indicated that oocyte donors who were married or living together with someone showed significantly higher scores on $\mathrm{SD}(\mathrm{p}=0,041)$ (mean 33,9 $\pm 6,8)$ compared to women who were single $(31,2 \pm 6,9)$. This indicates that these women described themselves as more responsible and felt more purposeful, Self-acceptant and having a higher Congruent Second Nature than those who lived alone.

In order to compare the personality characteristics of the women who donated their oocytes to a known recipient with those of donors who donated to unknown recipients we applied MANOVA and found no significant main effect (Pillai's trace $=.043 ; \mathrm{F}=1.25 ; \mathrm{p}=.279 ; \eta^{2}=$ .04 ; power $=.53$ ). However, there was a significant Between-Subjects Effect for Novelty Seeking $\left(\mathrm{F}=6.92 ; \mathrm{p}=.009 ; \eta^{2}=.03\right.$; power $\left.=.75\right)$ with anonymous donors scoring higher (mean $23.0 \pm 5.5)$ than did known donors $(20.3 \pm 5.0)$. These results imply that anonymous donors were perceiving themselves as a little easier to get excitable, feeling more impulsiveness and more disorderliness compared to those who know the recipient couple.

There was no significant association between educational levels for women who donated to a know recipient compared to the women who donated to an unknown recipient $(\chi 2=3.67 ; \mathrm{p}=$ 
.299). The association between family situation and "known" and "unknown" oocyte donors $(\chi 2=8.89 ; \mathrm{p}=.012)$ was significant. Among the donors who knew the oocyte recipient couples the percentage who were living alone was less than the percentage of donors who lived with a partner. The results from the TCI test indicate that the oocyte donors were all in the normal range of character. 


\section{Discussion}

In this nationwide oocyte donor program we found that the women who have been accepted for inclusion in the donation program were all well adjusted and mature in their personality. The result is not surprising since the donors were selected after medical and psychological assessments were made at the clinics. Although it is true that there is no standardized way for these assessments to be made - each clinic has its own routine - most clinics follow the programme described in the method section of this paper and the present results indicate that the selection process is functional, i.e. we get psychologically healthy and stable oocyte donors. This is, of course, reassuring for the medical profession and for the recipient couples but it is perhaps even potentially more reassuring for the child to be later in life. When that child becomes mature, he or she can be reassured that the donor most likely was psychologically sound at the time of the donation.

Earlier studies of personality characteristics of potential oocyte donors have revealed relatively high frequencies of symptoms of depression and anxiety. Klock and colleagues (13) showed that of 150 applicants $21 \%$ were rejected because of their psychological status. Those results indicate that measuring psychological health must be a requirement for all parties involved - the woman who is candidates for being oocyte donors, the recipient couples and the child to be. There are, of course, limitations to psychological tests, inventories and interviews as well as other means of evaluating personality, and earlier results indicate that potential commercial oocyte donors tend to minimize and hide certain aspect of their psychological health and wellbeing in order not to be excluded from the program $(13,14)$. Results from a recent study by Klock et al. (2009) showed that one of the most important results of the MMPI2 evaluation of oocyte donors was the need to "pay attention to the validity scale L when considering donor selection". The L Scale Also referred to as the "lie scale," this scale was developed to detect attempts by individuals to present themselves in a favorable light. People who score high on this scale deliberately try to present themselves in the most positive way possible, rejecting shortcomings or unfavorable characteristics. (14).

In the present study the oocyte donors described themselves as less worried, fearful, shy and fatigued and as more persistent compared to a comparison group of women. This set of personality characteristics may increase the probability for success in carrying out different 
tasks and might be of significance for the individual's management of their donation both in a long term as well as in short term

The donors in the present study who were known to recipients displayed scores indicating maturity and responsibility in parity with a comparison group of women. These particular characteristics are important, as might well be assumed, and it is important that this fact be part of future discussions and recommendation for couples and donors who come to know each other. The Swedish National Board of Health and Welfare (12) recommends that cross donation should be practiced. This requires that the couple who are to receive the donation receive their oocyte from an unknown donor and their donor give her oocyte to a couple unknown for her. This is to minimize risk situations for the future for all involved. The advantage with evaluation with TCI is not just that the team has a measurement of the character and maturity of the individual but also knowledge of temperament and its biological correlates since extremely low values on in character dimensions is strongly associated with different mental illnesses.

The use of oocyte donation continues to increase and, given this increase, the number of women in Sweden who will apply to be oocyte donors will also increase. There are indications that up to $44 \%$ of the women who apply to be oocyte donors will ultimately be rejected because of medical or psychosocial reasons (16). For these women the rejection may have a very negative influence on their wellbeing and also on their future reproductive history. The profession dealing with oocyte donors must therefore give these women the opportunity to get counseling that allows time for reflection between meetings (16).

Despite the careful advice of the most experienced team, no one can predict how someone will feel tomorrow about their decision to donate gametes, let alone how they will feel 20 years in the future. The results from this study indicate that the procedures involved in recruiting and accepting donors in a non- commercial donor program are functioning well, which is reassuring for recipient couples, the child to be, lawmakers and medical professionals and, of course, for the donor herself.

\section{ACKNOWLEDGEMENTS}


This study was supported by grants from the Medical Research Council of Southeast Sweden (FORSS). We thank all the personal at the 7 IVF-Clinics that have been involved in this study. We also thank Merck Serono for valuable support during the implementation of the study.

Conflicts of interest: None

Financial disclosure: None.

\section{Contribution to Authorship}

Gunilla Sydsjö Research idea, design, preparation of the manuscript, responsible for the final preparation of the manuscript

Claudia Lampic Research idea, design, preparation of the manuscript,

Sven Brändström Analysis of data, preparation of the manuscript

Johannes Gudmundsson Data collection, preparation of the manuscript

Per-Olof Karlström Data collection, preparation of the manuscript

Ann Kjellberg-Thurin Data collection, preparation of the manuscript

Nils Gunnar Solensten Data collection, preparation of the manuscript

Agenta Skoog Svanberg Data collection, design, preparation of the manuscript, analysis of data

\section{Ethics}

Human Research Ethics Committee; Faculty of Health Sciences, Linköping University nr Dnr: M129-05-050223, T113-07 080122 approved the study.

\section{Word Count}




\section{References}

1. Purewal A, van den Akker O. Systematic review of oocyte donation: investigating attitudes, motivation and experiences. Hum Reprod Update. 2009 Sep-Oct;15(5):499-515. Epub 2009 May 14. Review.

2. Purewal S, van den Akker O. Attitudes and intention to donate oocytes for research. Fertil Steril. 2010 Mar 1;93(4):1080-7. Epub 2009 Jan 9.

3. Purewal S, van den Akker OB. British women's attitudes towards oocyte donation: ethnic differences and altruism. Patient Educ Couns. 2006 Dec;64(1-3):43-9. Epub 2006 Jan 19. 4. Hyde MK, White KM. Disclosing donation decisions: the role of organ donor prototypes in an extended theory of planned behaviour. Health Educ Res. 2009 Dec;24(6):1080-92. Epub 2009 Jun 12.

5. Hyde MK, White KM. Are organ donation communication decisions reasoned or reactive? A test of the utility of an augmented theory of planned behaviour with the prototype/willingness model. Br J Health Psychol. 2010 May;15(Pt 2):435-52. Epub 2009 Sep 18.

6. Cloninger C.R. (2004), Feeling Good: The Science of Well Being. New York: Oxford University Press.

7. Brändström S, Sigvardsson S, Nylander PO, Richter J.The Swedish Version of the Temperament and Character Inventory (TCI). A cross-validation of age and gender influences. European Journal of Psychological Assessment. 2008;24, 14-21.

8. Cloninger C. R, Przybeck T. R, Svrakic D. M, Wetzel R. D. (1994). The Temperament and Character Inventory (TCI). A guide to its development and use. St. Louis, Missouri: Center for Psychobiology of Personality, Washington University.

9. Brändstrom, S., Schlette, P., Przybeck, T. R., Lundberg, M., Forsgren, T., Sigvardsson, S., Nylander, P. O., Nilsson, L. G., Cloninger, R. C., \& Adolfsson, R. Swedish normative data on personality using the Temperament and Character Inventory. Comprehensive Psychiatry $1998 ; 39,122-128$.

10. Engström C, Brändström S, Sigvardsson S, Cloninger C. R, Nylander, P.O. Bipolar disorder III. Harm avoidance a risk factor for suicide attempts. Bipolar Disorder 2004;6, 130138.

11. Pettersson K, Brändström S, Toolanen G, Hildingsson C, Nylander, P. O. Temperament and character: prognostic factors in whiplash patients? European Spine Journal 2004;6, 130138.

12. The National Board of Health and Welfare SOSFS 2006:10 (M) Stockholm 2006. 
13. Klock SC, Stout JE; Davidson M. Analysis of Minnesota Multiphasic Personality Inventory-2 profiles of prospective anonymous oocyte donors in relation to the outcome of the selection process. Fertil Steril 1999;72:1066-1072.

14 Kalfoglou AL. Geller G. Navigating conflicts of interest in oocyte donation: an analysis of donors' experience. Women's Health Issues 2000;10:226-239.

15. Klock SC, and Covington SN Minnesota Multiphasic Personality Inventory (MMPI-2) profiles in the assessment of ovum donors. Fertil Steril. 2009 Oct 13. [Epub ahead of print] 16. Zweifel JE, Biaggio B, Schouweiler C, Lindheim SR. Follow-up assessment of excluded oocyte donor candidates. J Obstet Gynaecol Res. 2009;35:320-5 
Table1. Socio demographics of the oocyte donors.

Donors

$\mathrm{N}=181$

\section{Education}

1. Comprehensive school

8

2. Senior high school

3. Senior high school + some college

4. University

82

5. Data missing

1

Family situation:

1. Single

2. Have a partner 18

3. Married/cohabiting 118

4. Data missing

Biological children of their own 
Table 2. Temperament and Character dimensions (TCI) for oocyte donors and the comparison group.

$$
\text { Donors Controls T-test }
$$

\section{Temperament}

Novelty Seeking

$22.6 \pm 5.5$

$22.5 \pm 5.6 \quad \mathrm{~ns}$

Harm Avoidance

$12.1 \pm 5.7$

$14.7 \pm 6.0 \quad \mathrm{P}<0.01$

Reward Dependency

$16.6 \pm 3.1$

$16.7 \pm 3.5$

ns

Persistence

$4.6 \pm 2.0$

$4.1 \pm 1.8$

$\mathrm{P}<0.5$

\section{Character}

Self Directedness

$33.1 \pm 6.8$

$32.4 \pm 7.2$

ns

Cooperativeness

$35.0 \pm 4.2$

$34.4 \pm 4.7$

ns

Self-Trancendence

$12.8 \pm 5.4$

$12.7 \pm 5.6$

ns 
